\title{
Implementação de barragens para aproveitamentos hidrelétricos: os desdobramentos da instalação de PCH's no rio Cuiabá, Cuiabá - MT
}

Implementation of dams for hydroelectric power plants: the consequences of the installation of SHPs on the Cuiabá River, Cuiabá - MT

Implementación de presas para centrales hidroeléctricas: las consecuencias de la instalación de PCH en el río Cuiabá, Cuiabá - MT

\section{Resumo}

O estudo visa às dinâmicas circunstanciais em torno do licenciamento ambiental de pequenas centrais hidrelétricas (PCH's) no estado de Mato Grosso. O mesmo, caracteriza-se como qualitativo, baseando - se na intenção de instalação de PCH's no rio Cuiabá - MT, com informações provenientes de estudos de vários artigos, dissertações, teses e de consultas realizadas no acervo da Agência Nacional de Energia Elétrica, da Agência Nacional de águas e Saneamento Básico e da mídia local. Verifica-se, em suma, que o problema não está sobre a capacidade do licenciamento, e sim sobre os conflitos e possíveis impactos que possam vir a serem gerados a partir da implantação das PCH's, na biodiversidade geral, nas comunidades ribeirinhas que vivem em seu entorno e à jusante do rio, e principalmente na reprodução dos peixes. O estudo demostra uma ocorrência distinta da comunidade em relação à implementação das PCH's no trecho do rio Cuiabá, pois em comparação a outros projetos de implementação no Estado, ganhou particular atenção de diferentes membros da sociedade, como promotores, juízes, deputados, bem como do setor acadêmico, não sendo somente da comunidade ribeirinha, demonstrando que a implementação das PCH's no Rio Cuiabá, além dos impactos comumente conhecidos, demostra que a importância do rio vai além dos aspectos ambientais, promovendo comoção entre os moradores da região.

Palavras-chave: Pantanal; Licenciamento; Conflito socioambiental.

\begin{abstract}
The study aims at the circumstantial dynamics surrounding the environmental licensing of small hydroelectric plants (PCHs) in the state of Mato Grosso. It is characterized as qualitative, based on the intention to install SHPs in the Cuiabá River - MT, with information from studies of several articles, dissertations, theses and consultations carried out in the collection of the National Electric Energy Agency, of the National Water and Sanitation Agency and local media. It appears, in short, that the problem is not about the licensing capacity, but about the conflicts and possible impacts that may be generated from the implementation of SHPs, in general biodiversity, in the riverside communities that live in its around and downstream of the river, and mainly in fish reproduction. The study demonstrates a distinct occurrence of the community in relation to the implementation of SHPs in the Cuiabá river stretch, as compared to other implementation projects in the State, it gained particular attention from different members of society, such as prosecutors, judges, deputies, as well as from the academic sector, not only from the riverside community, demonstrating that the implementation of SHPs on the Cuiabá River, in addition to the commonly known impacts, demonstrates that the river's importance goes beyond environmental aspects, promoting commotion among the region's residents.
\end{abstract}

Keywords: Pantanal; Licensing; Socioenvironmental conflict. 


\begin{abstract}
Resumen
El estudio apunta a la dinámica circunstancial en torno al licenciamiento ambiental de pequeñas centrales hidroeléctricas (PCH) en el estado de Mato Grosso. Se caracteriza por ser cualitativo, con base en la intención de instalar PCH en el río Cuiabá - MT, con información de estudios de varios artículos, disertaciones, tesis y consultas realizadas en la colección de la Agencia Nacional de Energía Eléctrica, de la Agencia Nacional de Agua y Agua. Agencia de Saneamiento Básico y medios locales. Parece, en definitiva, que el problema no es de la capacidad de licenciamiento, sino de los conflictos y posibles impactos que se puedan generar por la implementación de PCS, en general la biodiversidad, en las comunidades ribereñas que habitan en sus alrededores y aguas abajo del río, y principalmente en la reproducción de peces. El estudio demuestra una ocurrencia distinta de la comunidad en relación a la implementación de PCH en el tramo del río Cuiabá, en comparación con otros proyectos de implementación en el Estado, ganó particular atención de diferentes miembros de la sociedad, como fiscales, jueces, diputados, así como el sector académico, no solo de la comunidad ribereña, demostrando que la implementación de PCS en el río Cuiabá, además de los impactos comúnmente conocidos, demuestra que la importancia del río va más allá de los aspectos ambientales, promoviendo conmoción entre los pobladores de la región.
\end{abstract}

Palabras clave: Pantanal; Licencia; Conflicto socioambiental.

\title{
1. Introdução
}

Ante a geração de eletricidade a partir dos combustíveis fósseis (derivados de petróleo, carvão mineral e gás natural), a energia hidrelétrica que utiliza como combustível a água, é apresentada como uma fonte energética "limpa, renovável e barata". A hidreletricidade se constitui numa alternativa de obtenção de energia elétrica a partir do aproveitamento do potencial hidráulico de um determinado trecho de um rio, normalmente assegurado pela construção de uma barragem e pela consequente formação de um reservatório (Bermann, 2007).

A utilização da energia elétrica tornou-se essencial no mundo contemporâneo, pois quase todas as atividades humanas envolvem o seu consumo. O quão essencial é seu fornecimento, somente é percebido quando o mesmo é interrompido por alguma falha do sistema. Perante essa perspectiva, sua análise jurídica, com reflexos nas mais diversas ordens, tem sido cada vez mais alvo de discussões importantes (Terrin \& Blanchet, 2019).

Do ponto de vista da utilização dos recursos hídricos, a geração de eletricidade no Brasil tem sido considerada uma prioridade, apesar de uma legislação antiga que já estabelecia os princípios do uso múltiplo das águas, como o Código das Águas de 1934. A Lei $\mathrm{n}^{\circ}$. 9.433, de 8 de janeiro de 1997, que define a Política Nacional de Recursos Hídricos e os instrumentos do Sistema Nacional de Gerenciamento de Recursos Hídricos, apenas reafirma esses princípios, sem tornar efetiva a sua execução (Bermann, 2007).

Hoje o Brasil é um dos maiores construtores de barragens mundiais e o segundo país que gera mais energia hidrelétrica no mundo, atrás da China, com a hidroeletricidade representando $12,6 \%$ do total de energia consumida domesticamente e $68,1 \%$ da eletricidade do país (Oliveira, 2018).

Está previsto que a demanda por energia continue aumentando nos próximos anos, resultado, principalmente do crescimento populacional e do aumento do nível do consumo. Tendo em vista que a tendência é que fique cada vez mais difícil a implantação de grandes empreendimentos hidrelétricos, voltam ao interesse dos países a construção e revitalização das Pequenas Centrais Hidrelétricas (PCH’s) (Manzano-Agugliaro et al., 2013).

De acordo com a Agência Nacional de Energia Elétrica (Aneel), (2018), existem dois tipos de reservatórios: acumulação e fio d'água. Os primeiros, geralmente localizados na cabeceira dos rios, em locais de altas quedas d'água, dado o seu grande porte permitem o acúmulo de grande quantidade de água e funcionam como estoques a serem utilizados em períodos de estiagem. Pelo fato de localizarem a montante das demais hidrelétricas podem regular a vazão da água que irá fluir para elas, de forma a permitir a operação integrada do conjunto de usinas. As unidades a fio d'água geram energia com o fluxo de água do rio, ou seja, pela vazão com mínimo ou nenhum acúmulo do recurso hídrico. A queda d’água, no geral, é definida como de alta, baixa ou média altura, sendo considerada baixa queda uma altura de até 15 metros e alta queda, superior a 150 metros. 
A potência instalada determina se a usina é de grande ou médio porte ou uma Pequena Central Hidrelétrica ( $\mathrm{PCH})$. A potência instalada é a quantidade máxima de energia que pode ser produzida pela fonte de energia, em uma determinada unidade de tempo, sendo a capacidade máxima de produção de uma usina. Para verificar a eficiência, deve-se ter a máxima produção de energia determinada pela potência instalada. Para verificar se a capacidade produtiva de uma hidrelétrica está sendo usada, devese analisar a quantidade de energia produzida de acordo com a potência instalada. Caso esta tenha uma determinada capacidade instalada ociosa, logo não está sendo eficiente no uso de seu potencial (Sampaio; Ramos \& Sampaio, 2005).

Em resolução normativa recente, nº 895/2020 a Agência Nacional de Energia Elétrica (Aneel) adotou três classificações para exploração de aproveitamento hidrelétricos (AEH): Central Geradora Hidrelétrica - CGH (com até 5 MW de potência instalada), Pequena Central Hidrelétrica - PCH (entre 5 MW e 30 MW de potência instalada) e Usina Hidrelétrica de Energia UHE, (potência instalada superior a $5 \mathrm{MW}$ e igual ou inferior a $50 \mathrm{MW}$, desde que não sejam enquadrados como PCH e potência instalada com mais de $50 \mathrm{MW}$ ) (Aneel, 2020).

Cunha (2008) vislumbrou em seus estudos a possibilidade de possíveis impactos ambientais e comprometimentos dos usos múltiplos da água, para o caso de vários AHE’s na mesma bacia hidrográfica. Devendo avaliar a melhor divisão de quedas do aproveitamento e, no caso da operação, as vazões turbinadas para obter uma operação em cascata, levando em conta sua eficiência e o fato de que as centrais a montante aumentam a energia firme das centrais à jusante, pois podem aumentar o nível mínimo de água dos seus reservatórios.

Ainda conforme Cunha (2008), três grupos de Usinas Hidrelétricas (UHE) determinam diferenciados problemas e questões. As grandes UHE's, que dispõem de altos valores de energia firme, estão, em geral, associadas a maiores problemas ambientais e apresentam grandes reservas para situações de emergências. As pequenas centrais hidrelétricas ( $\mathrm{PCH})$, com pequena capacidade, pouco ou quase nenhum problema ambiental e pouca (ou nenhuma, dependendo da forma de operação) capacidade de reserva para situações emergenciais, apresentam alta flexibilidade para mudar rapidamente a quantidade e energia fornecida ao sistema devido às mudanças na demanda, são úteis para aumentar o rendimento global (atendendo a cargas locais, eliminam em porcentagem necessidade de mais transmissão e reduzem perdas) e apresentam características interessantes na seara do sistema interligado e do sistema isolado. As usinas médias são intermediárias entre as duas.

As PCH's têm como vantagem principal uma maior simplicidade na concepção e operação, e geralmente operam a fio d'água (Ardizzon et al., 2014). Com área máxima inundada de $13 \mathrm{~km}^{2}$, excluindo a calha do leito regular do rio (Aneel,2020). De acordo com Reis (2011) elas apresentam três características principais: rápida entrada no sistema de potência e flexibilidade para mudar rapidamente a quantidade de energia proporcionada ao sistema; baixos custos de operação, manutenção e de produção de energia; e propriedades mais suaves de inserção ambiental.

Perius e Carregaro (2012) afirmam em seus estudos que nem sempre os efeitos da construção e funcionamento das PCH's são ruins. Devem-se levar em conta também muitos aspectos positivos como: produção de energia; retenção de água regionalmente; aumento do potencial de água potável e de recursos hídricos reservados; criação de possibilidades de recreação e turismo; aumento do potencial de irrigação; melhoria da navegação e transporte; aumento da produção de peixes e da possibilidade de aquicultura; regulação do fluxo e inundações; maiores possibilidades de trabalho para a população local e diminuição de gases do efeito estufa. O cuidado com o meio ambiente no seu aspecto geral, tem seus benefícios suportados no projeto que, se bem estruturado, não haverá retorno apenas financeiro, mas, levará o progresso para a região do empreendimento sem grandes intervenções na natureza. Porém, diante do crescimento da demanda por energia elétrica, conclui-se que os incentivos às Pequenas Centrais Hidrelétricas, por serem consideradas uma forma de produção de energia com baixo impacto ambiental e uma energia "limpa" e renovável, criam atrativos para que sejam implantadas em regiões consideradas críticas em relação à falta de energia. 
Já Nilton (2009) relata que é evidente que uma PCH pode causar menor impacto do que uma grande central hidrelétrica, contudo, dentro das especificidades socioambientais de uma região, pode infligir impactos graves e irreversíveis para um bioma determinado e para as populações que nele e dele vivem. $\mathrm{O}$ autor ainda cita a necessidade de progredir e apelar para o bom senso, observar não apenas o que determina as regulamentações como avaliar o que a natureza oferece e permite sua utilização sem destruí-la e nem afetar qualquer tipo de vida.

Galvão (2016) examinou em sua tese o conflito socioambiental ocorrido no noroeste do Mato Grosso, entre uma população Indígena Aruak, os Enawene-Nawe, e um consórcio de empresas construtoras de pequenas centrais hidrelétricas (PCH's) no Rio Juruena (O Projeto Juruena). Segundo a autora a geração de energia propriamente dita não melhora necessariamente a vida das populações afetadas, nem mesmo a vida da população Enawene, que habita as proximidades das usinas, mas não se beneficia dessa energia. A energia gerada pelas PCH's no rio Juruena é muitas vezes transmitida para regiões distantes de onde é produzida, para regiões em que a demanda de energia é maior, como a região Sudeste - contribuindo para as desigualdades regionais.

Gomes (2014), enfocou no potencial de repotenciação de usinas hidrelétricas no Brasil e sua viabilização, definindo a repotenciação como o ato de melhorar os parâmetros atuais de uma usina, seja aumentando sua capacidade instalada, ou seu fator de capacidade, seja melhorando o rendimento, ou as características mecânicas/elétricas das suas máquinas. Relata que quanto mais obras de repotenciação forem realizadas, mais se posterga a necessidade de construção de algumas novas usinas. Sendo assim, o Brasil poderia ganhar a capacidade de produzir mais 11.000 MW de potência elétrica sem necessidade de construir novas usinas, apenas reformando e aproveitando espaços já existentes em hidrelétricas já instaladas. E afirma ainda que a repotenciação demanda um prazo muito menor do que a construção de uma usina nova, além de não gerar impactos ambientais adicionais e possuir menor custo.

Nos últimos anos, após a privatização do setor de produção e serviços, o governo federal tem incentivado a produção de energia por Pequenas Centrais Hidrelétrica (PCH's), promovendo a propagação destes empreendimentos em todo o país e, Mato Grosso figura em terceiro lugar no número de pequenas barragens (Lira, 2014).

De acordo com o Avaliação Ambiental Integrada (AAI), realizada pela EPE (Empresa de Pesquisa Energética) do Ministério de Minas e Energia, (2010), 40\% da energia gerada nessas usinas vai para produtores independentes, apenas $16 \%$ servem aos serviços públicos - sendo estimado que a maioria da energia seja destinada pra fora do estado do Mato Grosso.

Este trabalho tem como objetivo analisar através de pesquisas em bibliografias conexas, o andamento do processo da implantação de barragens para aproveitamentos hidrelétricos no rio Cuiabá, localizada no Estado de Mato Grosso, bem como os impactos produzidos ou não pela instalação dessas PCH's no trecho do rio, visando gerar informação à comunidade interessada, sobre os conflitos e interesses envolvidos no processo, e promover a conscientização dos responsáveis por instalações dessa natureza a explorar outras fontes alternativas menos impactantes.

\section{Metodologia}

\section{1 Área de estudo: o Rio Cuiabá}

Em 1722, foi encontrada a primeira jaziga de ouro no Rio Cuiabá, o que ocasionou a mudança da povoação para a área, iniciando a fundação da cidade. O então povoado à beira do rio oportunizou grandes diferenças aos colonizadores, onde todo comércio com São Paulo era feito por meio do Paraguai, do Cuiabá, do Vermelho e do São Lourenço. Pelo Cuiabá chegavam alimentos, remédios e roupas, além de novos exploradores que estavam interessados não só nas jazidas de ouro, mas nas terras férteis da região (Ibge, 2016). No passado, houve na região grandes atividades de migração atrás de ouro, e nos dias atuais, o 
Estado de Mato Grosso está na posição de um dos maiores produtores de grãos do Brasil, sendo considerado um dos principais celeiros do país (Libos, et al., 2003).

A região de Cuiabá na classificação de Köppen pertencem no Clima de Savana (Aw), no qual possui um clima tropical, com estação seca (outono-inverno) e estação chuvosa (primavera-verão) com temperatura média anual de $25^{\circ} \mathrm{C}$ e pluviosidade anual de 1.450mm (Maitelli,2005).

A Bacia do Rio Cuiabá - BHC, localizada no estado de Mato Grosso é formada pelos rios Cuiabá da Larga (nascente principal) e Cuiabá do Bonito, que nascem nos vales da Serra Azul em Rosário Oeste (MT), a cerca de 500 m de altitude, na divisa natural entre as Regiões Hidrográficas Amazônica e do Paraguai, da qual faz parte, e tem o seu curso considerado até o Bairro do Porto, na cidade de Cuiabá a aproximadamente $158 \mathrm{~m}$ de altitude (Chiaranda, et al., 2016). Após a confluência, esses dois rios passam a se chamar Cuiabazinho, que por sua vez passa a se chamar Rio Cuiabá após o encontro com o Rio Manso, no município de Rosário Oeste, próximo à cidade de Nobres (Figueiredo, Dores \& Lima, 2018).

O principal rio da BHC o Cuiabá, é considerado um rio federal, com cerca de 750 quilômetros de extensão, percorre os estados de Mato Grosso e de Mato Grosso do Sul até a confluência com o Rio São Lourenço. Este, com 230 quilômetros, segue até o Rio Paraguai (Antaq, 2013; Marchetto et al., 2018).

O Rio Cuiabá subdivide-se em Alto, Médio e Baixo Cuiabá, (Figura 1), (IBGE, 2016). O Alto Cuiabá é caracterizado por apresentar uma vegetação do tipo cerrado em que a agricultura é uma das atividades predominantes, principalmente de soja, milho e arroz. Atividades de mineração de calcário e diamante ocorrem em menor escala na atualidade, estas são responsáveis pela contribuição do desmatamento de grandes áreas e alteração da mata ciliar. É uma região de planalto onde se concentra a maioria das nascentes da BHC, como as nascentes da sub-bacia do rio Manso e seus afluentes (Libos, et al., 2003; Oliveira et al., 2018).

Figura 1. Delimitação das sub-bacias do rio Cuiabá.

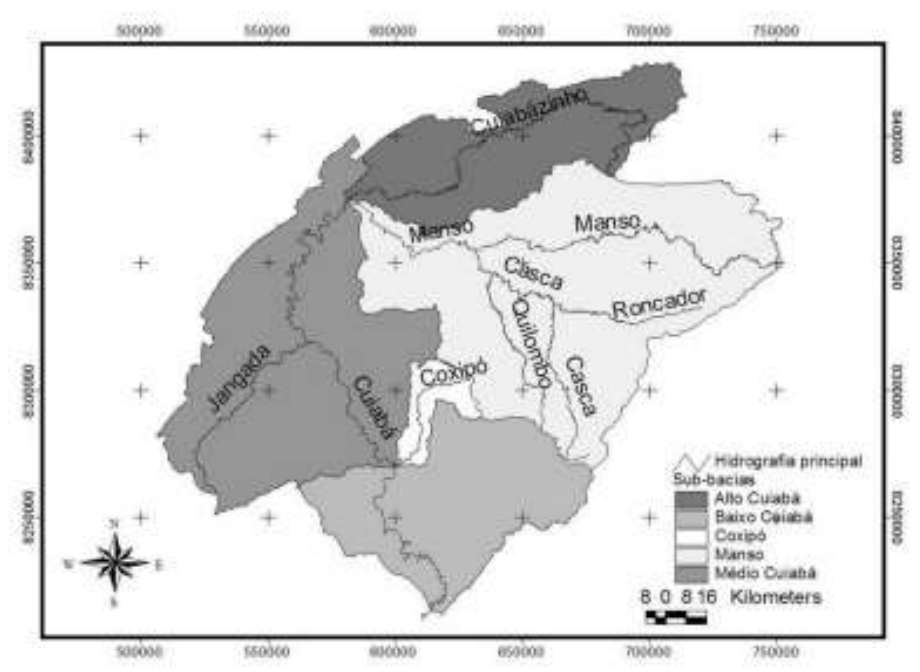

Fonte: Libos, et al. (2003).

A região do Médio Cuiabá, região conhecida como baixada cuiabana, compreende a área de depressão entre as partes mais altas do planalto e o início da área úmida. Apresenta vegetação mais diversificada, dos tipos: Cerrado, Cerradão, Floresta Estacional, Floresta Ripária, Formação Secundária e Florestas Remanescentes, a vegetação em diversas áreas apresenta alterações antrópicas devido ao uso inadequado da paisagem na forma de pastagens em áreas de solos pobres e, portanto, malformadas ou degradadas. A maior densidade populacional ocorre nessa região, nos municípios de Cuiabá, Várzea Grande, 
Nossa Senhora do Livramento, Santo Antônio do Leverger. E encontram-se diversas comunidades tradicionais ribeirinhas, entre as quais às de Sucuri, Bonsucesso e Barranco Alto (Libos, et al., 2003; Figueiredo e Salomão, 2009; Ferraz, 2016).

O baixo rio Cuiabá compreende os municípios de Barão de Melgaço e Poconé, está região é constituída de planície de inundação que é a área pantaneira de terras baixas, com baixa densidade populacional. A vegetação da região é caracterizada por Savana Parque, Savana Gramíneo, Floresta Estacional/ Savana. As atividades econômicas desenvolvidas são pecuária extensiva, pesca, turismo e mineração de ouro. O Baixo Cuiabá é um trecho em que a integridade ecológica depende principalmente da ecodinâmica das terras alta. Impactos ambientais negativos decorrentes das atividades antrópicas podem alterar no tempo e no espaço a estrutura (diversidade) das comunidades bióticas e no funcionamento (pulso de inundação) do rio Cuiabá e influenciar a dinâmica hídrica do Pantanal, influenciando na conectividade deste ambiente alagável (Libos, et.al., 2003; Figueiredo e Salomão, 2009; Ferraz, 2016).

A rede de drenagem é constituída pelo Rio Cuiabá e seus formadores, o rio Cuiabá da Larga e o Cuiabá do Bonito, todos de águas perenes, assim como os seus principais tributários, que são pela margem esquerda, os rios: Marzagão, Manso, Acorizal e Coxipó-Açu; e pela margem direita Chiqueirão, Jangada, Espinheiro e Pari (Figura 2) (Chiaranda, et al., 2016).

Figura 2. Rede de drenagem da Bacia Hidrográfica do Rio Cuiabá.

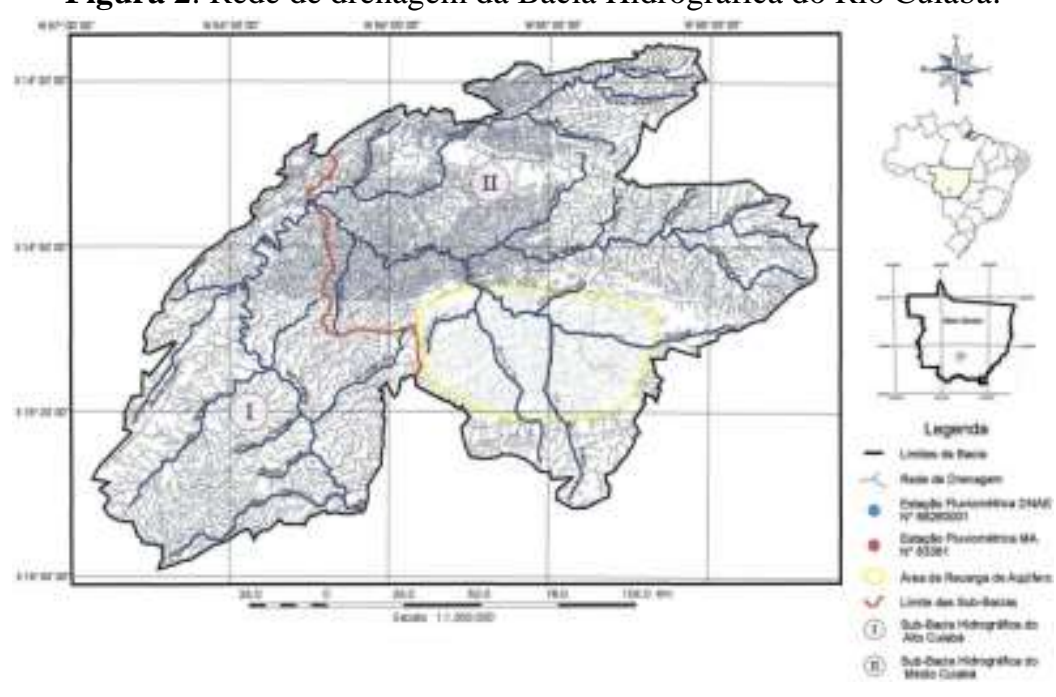

Fonte: Chiaranda, et. al. (2016).

O Rio Cuiabá é de relevante importância social e econômica como capital natural e cultural, decorrente dos serviços de regulação, produção, suporte e cultural prestados por este ecossistema alagável, cruciais para a conservação da diversidade biológica e cultural do Pantanal e para manutenção do bem estar humano dos usuários diretos e indiretos desta bacia hidrográfica (Ferraz, 2016).

\subsection{Procedimentos metodológicos}

Esta pesquisa é de natureza aplicada e de objetivo exploratória, a fim de proporcionar maior familiaridade com o problema, tornando-o mais explícito. Utilizou-se do levantamento bibliográfico baseada em artigos e livros, e da pesquisa documental baseando em dados secundários, por meio de documentos, notas, leis, textos jornalísticos entre outros. Quanto à abordagem foi adotada a técnica de análise qualitativa, por ser conjunto de práticas que transformam o mundo visível em dados representativos, incluindo notas, entrevistas, fotografias, registros e lembretes (Creswell \& Creswell, 2021).

A definição deste estudo envolveu o site da Agência Nacional de Energia Elétrica (Aneel), que com o novo Sistema de Informações de Geração (Siga) informa o número dos empreendimentos hidrelétricos existentes em Mato Grosso e o estágio de 
cada um deles. Utilizou-se o estudo elaborado pela Agência Nacional da água e Saneamento Básico (Ana), a qual se trata da avaliação dos efeitos da implantação de empreendimentos hidrelétricos na Região Hidrográfica do Paraguai, no âmbito do Plano de Recursos Hídricos da RH-Paraguai - PRH Paraguai, de pesquisa multidisciplinar dividida em hidrologia; qualidade da água e sedimentologia; ictiofauna; e socioeconomia e energia.

\section{Resultados e Discussão}

No que se refere a capacidade instalada, dos 159 números de empreendimentos, os 3.223.673,10 (kW) são de potência outorgada e 2.990.656,10 (kW) são de potência fiscalizada (Tabela 1):

Tabela 1. Frequência de usinas hidrelétricas no estado de Mato Grosso.

\begin{tabular}{ccccc}
\hline Fonte & Potência Outorgada $(\mathbf{k W})$ & Potência Fiscalizada $(\mathbf{k W})$ & Quantidade & $\boldsymbol{\%}$ \\
\hline UHE & $1.877 .650,00$ & $1.882 .750,00$ & 12 & $58,25 \%$ \\
PCH & $1.270 .554,00$ & $1.032 .346,00$ & 83 & $39,41 \%$ \\
CGH & $75.469,10$ & $75.469,10$ & 64 & $2,34 \%$ \\
\hline Total & $3.223 .673,10$ & $2.990 .565,10$ & 159 & $100,00 \%$ \\
\hline
\end{tabular}

Fonte: Aneel (2021).

Relativo a Potência Outorgada são aqueles considerados no Ato de Outorga, são para os empreendimentos registrados (empreendimentos que não possuem necessidade de emissão de Ato de outorga) relativos às potências instaladas dos empreendimentos. Já a Potência Fiscalizada é considerada a partir da operação comercial de cada unidade geradora (Aneel, 2020).

Atualmente, a bacia do Rio Cuiabá, dentro do Estado de Mato Grosso, apresenta PCH's, em diversas etapas do processo de concessão, outorga e licenciamento. Estudos elaborados pela Ana (2020) relatam que na bacia do Rio Cuiabá constam 25 empreendimentos hidrelétricos (Figura 3), distribuídos da seguinte forma: 9 em operação; 1 com construção não iniciada; 8 previstos; 7 eixos disponíveis. 
Figura 3. Aproveitamentos hidrelétricos na bacia do rio Cuiabá.

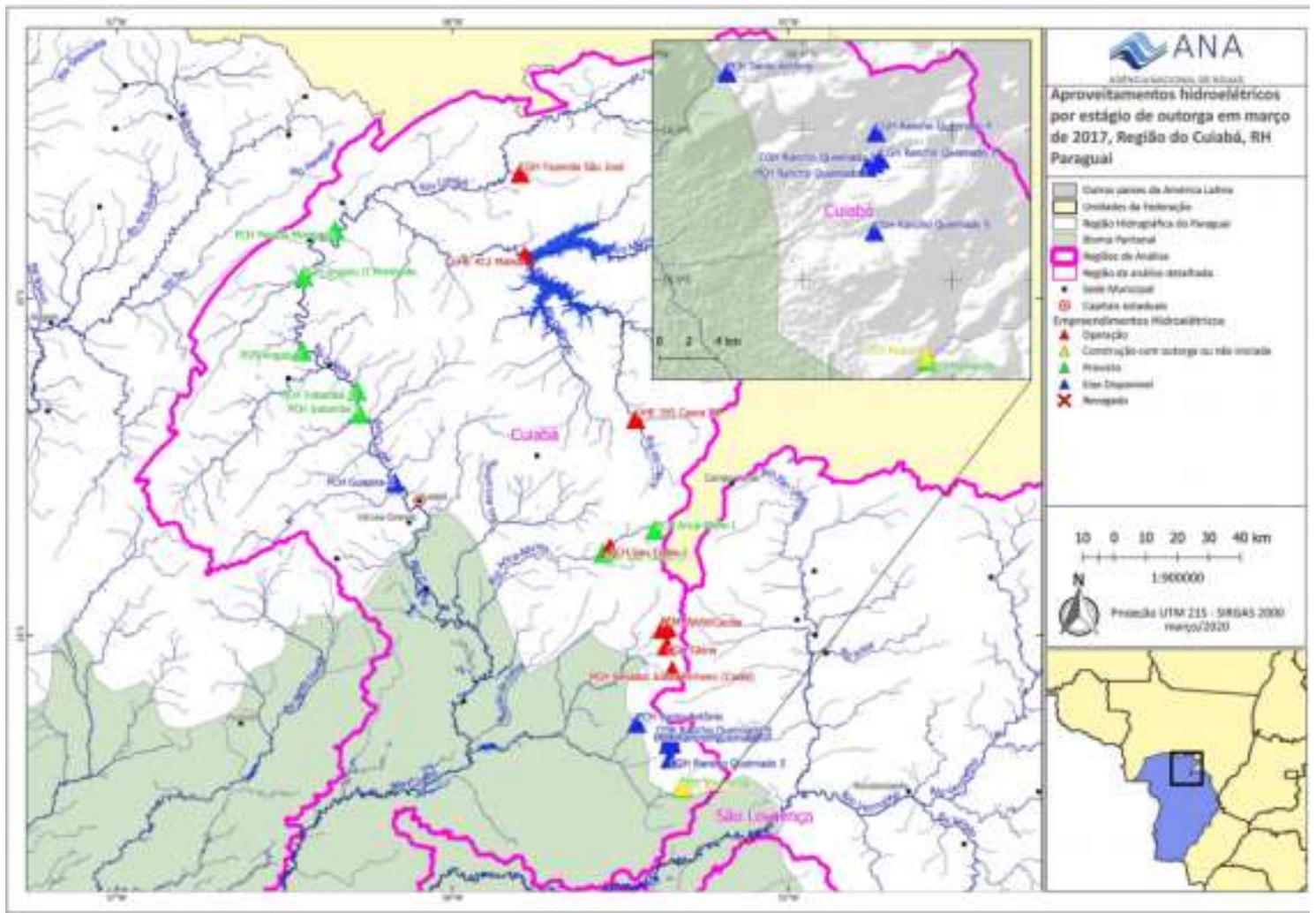

Fonte: ANA (2020).

Com o intuito de simplificar os procedimentos de submissão e análise dos requerimentos, bem como a gestão de outorgas dos empreendimentos de geração de energia, a Agência Nacional de Energia Elétrica - Aneel, publicou a Resolução Normativa n ${ }^{\circ}$ 875/2020. Resumidamente, trata dos requisitos e procedimentos necessários à realização dos Estudos de Inventário Hidrelétricos de bacias hidrográficas; à obtenção de outorga de autorização para exploração de aproveitamentos hidrelétricosAEH, com potência superior a $5.000 \mathrm{~kW}$ e igual ou inferior a $50.000 \mathrm{~kW}$ a PCH; à comunicação de implantação de Central Geradora Hidrelétrica com capacidade instalada reduzida, com potência igual ou inferior a 5.000 kW, a CGH; e à aprovação de Estudos de Viabilidade Técnica e Econômica de Usina Hidrelétrica sujeita à concessão, com potência superior a $50.000 \mathrm{~kW}$ a UEH (Brasil, 2020).

Quanto à outorga de autorização para exploração de aproveitamentos hidrelétricos, esta prevê o procedimento para obtenção do Despacho de Registro de Intenção à Outorga de Autorização (DRI), cuja publicação dará ensejo à elaboração do Projeto Básico e do Sumário Executivo do empreendimento dentro do prazo de 14 (quatorze) meses. A ANEEL analisará o Sumário Executivo, que deverá ser compatível com os Estudos de Inventário Hidrelétrico e com o uso do potencial hidráulico, decidindo pela publicação ou não do Despacho de Registro da Adequabilidade do Sumário Executivo (DRS), o que permitirá que a ANEEL solicite a Declaração de Reserva de Disponibilidade Hídrica (DRDH) e que o interessado requeira o Licenciamento Ambiental pertinente.

Após a obtenção da DRDH e do Licenciamento Ambiental, o interessado cujo empreendimento é objeto de DRS válido deverá apresentar o requerimento de outorga de autorização, que deverá ser acompanhado dos documentos indicados no Anexo IV da Resolução (Garantia de fiel cumprimento; Regularidade Fiscal; Qualificação jurídica; Qualificação Técnica). Atendidos os requisitos necessários, a ANEEL emitirá a outorga de autorização que terá vigência de 35 (trinta e cinco) anos (Brasil, 2020). 
Aneel (2020) informa que em Mato Grosso existem 142 empreendimentos hidrelétricos em estágio de operação, que são aquelas que iniciaram a operação comercial a partir da primeira unidade geradora; 06 em construção, aquelas que obtiveram a licença ambiental de instalação e iniciaram as obras locais; e 11 com construção não iniciada, são as usinas outorgadas: aquelas que receberam Ato de Outorga (Concessão ou Autorização) e ainda não iniciaram as obras.

\subsection{Impactos na construção da PCH}

De acordo com Aneel (2021) o município de Cuiabá possui somente 1 empreendimento em operação, de fonte CGH Central geradora hidrelétrica, com Potência outorgada e potência fiscalizada de 279,90 (KW). No entanto consta mais especificadamente na relação dos empreendimentos hidrelétricos 6 DRS (Despacho de Adequação do Sumário executivo), do tipo PCH, com data de solicitação dos anos 2017 a 2020, com validade até 2024. Informando o interesse na instalação das PCH's no trecho do rio Cuiabá.

A escolha dos estudos/empreendimentos baseou-se nos conflitos existentes na implantação da PCHS no Rio Cuiabá, observados em diferentes canais de informação, sendo então as escolhidas para subsidiar a pesquisa. Como o processo já possui o DRS, fez se necessário a análise dos diversos fatores que estão sendo levantados em favor ou desfavor da implementação dessas PCH's.

Na Figura 4, são mostradas as zonas de conflito e as represas em processo de licenciamento no rio Cuiabá, onde os pontos em amarelo, alinhados, seriam as seis PCHs no leito do Rio Cuiabá.

Figura 4. Estudo dos impactos de infraestruturas na Bacia do alto Paraguai (BAP).

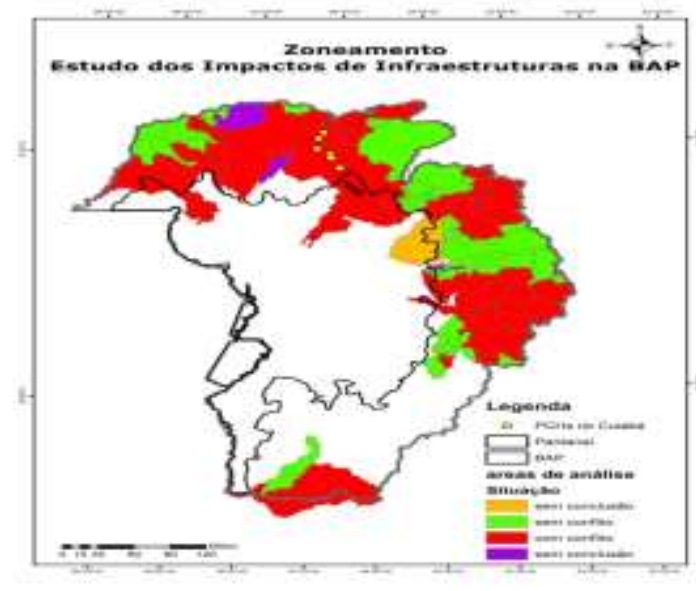

Fonte: ANA (2020).

Segundo Agência Nacional de Águas e Saneamento básico (ANA, 2020), as seis represas que estão previstas para serem instaladas ao longo do Rio Cuiabá, estão na zona vermelha, ou seja, zona de grande impacto ambiental para toda a Bacia do Alto rio Paraguai (BAP). São elas: Angatu I, Angatu II, Iratambé I, Iratambé II, Guapira II, e Perudá, previstas para serem instaladas no estado de Mato Grosso, nos municípios de Nobres, Rosário Oeste, Jangada, Acorizal, Várzea Grande e Cuiabá.

De acordo com a ANA (2020), os impactos vão desde a perda da conectividade entre planície e planalto, o que afeta diretamente no processo migratório dos peixes, a perda de nutrientes e sedimentos importantes para a sobrevivência dos rios, até a alteração do regime hidrológico, que poderá ser sentida em toda a planície pantaneira.

Segundo Márcia Divina, pesquisadora da Embrapa Pantanal, o Rio Cuiabá deve permanecer livre de represas. Durante evento promovido pela Ecoa (2021), em fevereiro deste ano, para análise das contribuições de estudos realizados pela Agência Nacional de Águas sobre os impactos das usinas hidrelétricas sobre o Pantanal e a Bacia do Alto Paraguai, Divina mostra um 
mapa no qual estão destacados os rios Sepotuba, Cuiabá, Itiquira e todo o sistema do Taquari, dizendo que devem ficar com o fluxo de nutrientes e sedimentos livres:

"A gente não pode perder essa conectividade de planície e planalto com esses barramentos nos rios, eles vão provocar mudanças significativas. A nossa sugestão é que esses rios fiquem livres de barramento”, diz a pesquisadora.

Segundo Fernando Villela, sócio da Maturati Participações, responsável pelo projeto das seis PCHs no trecho entre as cidades de Cuiabá e Nobres, as hidrelétricas não vão impedir a passagem dos peixes pois oito comportas de oito metros de largura por oito de altura, em todas as seis PCHs, serão abertas no período de piracema (globo.com., 2021).

“Teremos 64 metros de rio para passagem onde hoje tem cerca de 100 metros. Os peixes vão subir. Não faríamos um projeto sem nos preocuparmos com isso. O ponto mais importante foi a transposição dos peixes” afirma Villela.

Segundo ele, as barragens terão entre 5,5 e 9 metros de altura e serão abertos também caminhos alternativos para que a piracema ocorra, como as chamadas escadas de peixes e vertedouros livres. O fluxo de águas será constante. O projeto custará R \$ 1,8 bilhão, que serão captados de fundos de investimento. A estimativa é que fique pronto entre 24 e 36 meses após a emissão da licença de instalação, ainda sem data.

Em audiência pública na Assembleia Legislativa do estado de Mato Grosso, pesquisadores e especialistas explicaram os riscos da liberação dessas seis PCHs, que fazem parte de um pacote de 133 PCHs previstas para a bacia do Alto Paraguai (BAP), que alimenta o Pantanal, e se somariam às 47 hidrelétricas já implantadas na bacia, (Lucatelli, 2021).

O deputado estadual Lúdio Cabral (PT), que requereu a audiência pública realizada em 28 de junho de 2021 para debater o tema:

“A Agência Nacional de Águas (ANA) impôs restrição a PCHs na bacia do Alto Paraguai. Mesmo assim, há 133 projetos em andamento, sendo seis PCHs no Rio Cuiabá acima da cidade de Cuiabá, um intervalo muito curto para esse volume de empreendimentos hidrelétricos. Isso sacrifica toda a cadeia pesqueira no Pantanal e há impacto no ciclo de seca e cheia do bioma. Já há comprometimento severo do regime de águas que alimenta o Pantanal, com rios, baías e o Pantanal como um todo com escassez de água. Se esse volume de PCHs prosseguir, estaremos decretando a morte do Rio Cuiabá e do Pantanal”.

\subsection{Impactos na reprodução dos peixes}

Pesquisador da Embrapa que realizou estudos na bacia do Rio Paraguai a pedido da ANA (2020), Agostinho Catella, explicou que $90 \%$ dos peixes pescados na bacia são de piracema, ou seja, peixes migratórios que sobem os rios para se reproduzir (sendo o Rio Cuiabá um dos principais para reprodução dos peixes), e são muito afetados pelas PCHs.

Segundo Agostinho Catella:

"O que acontece quando temos uma represa? Se antes tínhamos um rio correndo livremente, agora temos uma barreira. Opeixe não chega lá em cima. E o ambiente lá em cima transformado num lago muda completamente a ecologia que existia antes para o retorno dos peixes, ovos e larvas".

Catella apresentou ainda, dados que mostram que o Rio Cuiabá é o mais importante para a economia pesqueira no Pantanal. Dos 7.667 pescadores profissionais artesanais do Pantanal, 4.142 estão na sub-bacia do Rio Cuiabá e 3.704 pescadores estão no Rio Cuiabá. Todos eles praticam a pesca de subsistência para manter suas famílias, de modo que cerca de 13 mil pessoas vivem da pesca e conseguem renda total de $\mathrm{R}$ \$26,1 milhões por ano somente no Rio Cuiabá. Na bacia que alimenta o Pantanal, os mais de 7 mil pescadores faturam R\$ 69,8 milhões por ano. Além desse valor que é conseguido pelos pescadores na venda do peixe, há toda uma cadeia de insumos e de revenda do pescado que movimenta a economia regional. 


\subsection{Impactos na biodiversidade}

De acordo com Lucatelli (2021), Fernando Tortato, pesquisador do Instituto Panthera, que estuda e protege grandes felinos, explicou os impactos das barragens em toda a biodiversidade pantaneira:

"O Pantanal é muito dependente dos ciclos hidrológicos. Com mais de 130 hidrelétricas previstas na bacia, há o risco de impactos sinergéticos, ou seja, o acúmulo de projetos e intervenções podem comprometer o pulso de inundação, a ciclagem dos nutrientes dentro do Pantanal, o processo migratório de peixes. Isso reduz a quantidade de aves aquáticas, répteis aquáticos e onças pintadas. Os peixes são muito importantes na dieta da onça pintada. Mesmo o predador de topo depende da biodiversidade do Pantanal", afirmou.

O promotor de justiça Marcelo Vachianno fez ainda, os seguintes questionamentos:

“Com essas barragens, a água passa a ter uso somente para produção de energia. Esses empreendimentos causam sérios prejuizos à segurança alimentar dos moradores e ao ecossistema. É importante refletirmos: o que Mato Grosso ganha? Quem está lucrando com isso? Temos que ponderar os riscos do potencial uso do ecoturismo, a segurança alimentar dos pescadores, da cadeia produtiva, serviços ecossistêmicos, conectividade entre planície e planalto e alteração do regime hidrológico".

A advogada da empresa Maturati Participações, informou que o processo de outorga na Agência Nacional de Energia Elétrica (Aneel) teve início em abril de 2010, o processo de licenciamento na Secretaria de Estado de Meio Ambiente de Mato Grosso (Sema/MT) em abril de 2019 e pedido de outorga na Agência Nacional de Águas (ANA) foi feito em junho de 2020. O representante da Sema, Eneas Figueiredo, disse que o processo está em análise.

Coautor da audiência, o deputado Wilson Santos (PSDB) propôs requerer os projetos detalhados das PCH's à Sema. “Os cientistas deixaram claro que essas hidrelétricas vão afetar o estoque peixeiro do Rio Cuiabá, principalmente os peixes nobres, que são peixes de piracema: pacu, pintado, peraputanga. O que vai acontecer com hotéis, pousadas, barcos pesqueiros do Pantanal e com essa economia que depende dessas espécies de peixes?”, questionou Wilson.

E ainda, o deputado Allan Kardec (PDT) fez a seguinte ponderação:

"Muitos sedimentos orgânicos passam por essas águas e alimentam a flora do Pantanal e toda a cadeia produtiva dessa flora, inclusive o mel. Se água fica represada e deixa de descer, também não temos mais essa vegetação no Pantanal. Já estamos vivendo a seca nas baías, bocainas, vazantes e arrombados".

Para a ecóloga Luciana Ferraz, representante do Fórum Nacional da Sociedade Civil nos Comitês de Bacias Hidrográficas (FONASC), as usinas que estão planejadas para funcionarem na parte média do rio Cuiabá poderão trazer impactos irreversíveis para as comunidades ribeirinhas e urbanas, para o ecossistema, caracterizado por espécies de peixes migratórios e, ainda, influenciar diretamente o Pantanal:

“Essas PCH's são de fio d'água, elas desviam o curso do rio e utilizam uma quantidade de água para gerar energia. Enquanto as Usinas Hidrelétricas (UHEs), como no caso de Manso, formam grandes represas. Mas, se observarmos uma PCH na sequência da outra, o impacto é sinérgico e negativo. Essas PCH's desviariam todo o curso do rio no Médio Cuiabá”.

O Ministério Público do Estado de Mato Grosso obteve liminar na Justiça que determina a suspensão imediata da análise e aprovação de processos de licenciamento ambiental e da emissão de outorgas para operação de Pequenas Centrais Hidrelétricas (PCH/UHE) em toda a bacia do Rio Cuiabá. A medida deverá se estender até que seja estabelecido estudo detalhado junto à Agência Nacional de Águas (ANA) sobre o tema. 
A determinação judicial foi proferida nos autos de uma Ação Civil Pública que requereu a adoção de medidas urgentes para salvar as baias Chacororé e Siá Mariana, localizadas na região do Pantanal. A Justiça estabeleceu também o prazo de 20 dias para que o Estado de Mato Grosso apresente plano de ação de curto, médio e longo prazos (todos com prazos específicos) com vistas à resolução, concreta e continuada, das questões relacionadas à redução no volume de água das duas baías.

A elaboração do Plano de Ação deverá levar em consideração os dados e recomendações contidos nos relatórios técnicos anexados à inicial. Entre os problemas apontados estão o assoreamento da área úmida dos ribeirões Cupim e Água Branca, em ambas as margens da Rodovia Estadual MT-040; obstrução do fluxo de água na Rodovia Estadual MT-040, em razão da elevação do aterro, instalação de manilhas acima do nível de base e da própria insuficiência das estruturas de drenagens para atender ao regime hidrológico característico do bioma pantaneiro; e construção de aterros, barragens, drenos e diques em diversas propriedades.

A ação cobra também providências no tocante à obstrução de corixos; alterações na qualidade da água e na vazão do Rio Cuiabá relacionadas à dinâmica de operação do reservatório do APM Manso; existência de estradas vicinais e de acesso às propriedades construídas sem a adoção da técnica adequada, assim obstruindo o fluxo de água; aumento do desmatamento em área de preservação permanente (APP) dos cursos hídricos e nas cabeceiras das nascentes; ocupações irregulares nas áreas de preservação permanente (APP's) e agricultura e pastagem intensiva em área de preservação permanente (APP).

Na liminar, o juiz Rodrigo Roberto Curvo determina que o Estado de Mato Grosso cumpra, no prazo de 20 dias, o plano de manejo sustentável da "Estrada Parque", Rodovia Estadual MT-040. Foi fixado multa de R\$150 mil por dia de descumprimento da presente ordem judicial.

Verifica-se que há divergência de opinião, alguns defendem amplamente a instalação das PCHS, visando o aspecto econômico, defendendo a tese da energia verde e do baixo impacto ambiental. De outro lado há autores e representantes da comunidade relatando os diferentes impactos da implantação de PCH’s na Bacia do rio Cuiabá. Para Lira (2014) o grande problema é a busca da padronização para esses empreendimentos, ou seja, a venda de pacotes prontos, desprezando a natureza e suas transformações naturais ou antrópicas sofridas ao longo do tempo, o que pode promover um impacto ainda maior.

Uma vez que o Brasil conta hoje com uma das maiores produções de energia elétrica do mundo, existe a necessidade de analisar de forma sinérgica os impactos socioambientais e econômicos, permitindo assim aos gestores, sociedade e diferentes entes da comunidade optar pela manutenção ou não desses empreendimentos energéticos.

Já no que diz respeito às sugestões para pesquisas futuras, com base nos resultados obtidos, recomenda-se o desenvolvimento dos seguintes trabalhos: Verificar o papel das políticas públicas como fator para a viabilidade e implantação das PCH's; Analisar de forma mais aprofundada a utilização das PCH's como vetor para interiorização do desenvolvimento industrial; e Estudar a cadeia produtiva das outras fontes renováveis, tais como a eólica, a solar e a biomassa, utilizando a metodologia aplicada nesta pesquisa.

É na resolução de conflitos na bacia hidrográfica que os entes devem avançar nas discussões sobre o tema das energias renováveis, mais especificamente, sobre os limites e potencialidades da sustentabilidade de fontes de energia.

\section{Conclusão}

Conclui-se que cada PCH apresenta características específicas, referentes, não apenas a sua localização, mas também, aos aspectos do seu projeto, uma limitação que pode ser apontada é o fato de que os resultados do estudo não podem ser generalizados e servem, apenas, como um guia para a realização de análises específicas mais aprofundadas.

Outro fator limitante encontrado foi a escassez de dados referentes aos documentos, processos de licenciamento das PCH's a serem implantadas, impossibilitando uma análise detalhada a respeito da construção das obras nos diferentes trechos do 
rio Cuiabá, o que impede de fornecer uma informação sobre qual seria os principais benefícios advindos da implantação, além dos já defendidos. Com isso a pesquisa identificou um maior número de opiniões contrárias à implantação das PCH’s na Bacia do rio Cuiabá.

Seria relevante a realização de estudos de outras fontes de energia para a capital de Mato Grosso, em consonância com o clima que lhe é característico. A região é conhecida pela grande ocorrência de incidência solar, tendo uma das temperaturas mais altas no Brasil em praticamente o ano todo. Com isso, visando a moderação no uso dos recursos hídricos, as novas pesquisas para verificar a viabilização do uso da energia solar na região, poderiam contribuir com a preservação desse recurso que é tão relevante, não só como combustível de energia elétrica, mas principalmente é essencial para a manutenção de todo ambiente.

\section{Referências}

ANA. (2021). Agência Nacional de Águas e Saneamento Básico. Estudos de avaliação dos efeitos da implantação de empreendimentos hidrelétricos. https://www.gov.br/ana/pt-br/assuntos/gestao-das-aguas/planos-e-estudos-sobre-rec-hidricos/plano-de-recursos-hidricos-rio-paraguai/estudos-de-avaliacaodos-efeitos-da-implantacao-de-empreendimentos-hidreletricos.

ANA. (2020). Agência Nacional de Águas e Saneamento Básico. Síntese dos Resultados para a bacia do rio Cuiabá (UPG/MT P4).

ANEEL. (2018). Agência Nacional de Energia Elétrica. Atlas de energia elétrica do Brasil (3a ed.). 236 pg. https://www.aneel.gov.br/cds//asset_publisher/54xgfe6dyWFA/content/atlas-de-energia-eletrica-do-bras-1/ 6568 35?in herit Redi rect=falsd

ANEEL. (2020). Agência Nacional de Energia Elétrica. Resolução normativa nº 875. Brasil.

ANEEL. (2020.) Agência Nacional de Energia Elétrica. Sistema de Informações de Geração da ANEEL - SIGA - Manual do usuário. https://app.powerbi.com/view?r=eyJrljoiNjc4OGYyYjQtYWM2ZCO0YjlLWJYMEtYzdkNTQ1MTc1NjM2liwidCI6jQwZDZmOWI4LWVjYTctNDZhMi05MmQ0LWVhNGU5Yz AxNzBIMSIsImMiOjR9

ANTAQ. (2013). Agência Nacional de Transportes Aquaviários. Bacia do Paraguai: Plano Nacional de Integração Hidroviária. Laboratório de Transportes e Logística - LABTRANS/Universidade Federal de Santa Catarina-UFSC. http://web.antaq.gov.br/portalv3/PNIH/BaciaParaguai.pdf

Ardizzon, G., Cavazzini, G. \& Pavesi, G. (2014). "A new generation of small hydro and pumped-hydro power plants: Advances and future challenges," Renewable and Sustainable Energy Reviews, Elsevier, vol. 31(C), p. 746-761.

Bermann, C. (2007). Impasses e controvérsias da hidroeletricidade. Estudos Avançados. 21(59), 139-153.

EPE. (2010). Empresa de Pesquisa Energética. Estudos de inventário hidrelétrico da bacia do rio Juruena relatório final - volume 25 - apêndice e - Avaliação Ambiental Integrada da Alternativa Selecionada.

Creswell, J. W., \& Creswell, J. D. (2021). Projeto de pesquisa: métodos qualitativo, quantitativo e misto. Penso.

Chiaranda, R., Colpini, C., \& Soares, T. S. (2016). Caracterização da Bacia Hidrográfica do Rio Cuiabá. Advances in Forestry Science Review. Adv. For. Sci., Cuiabá, v.3, p.13-20. https://periodicoscientificos.ufmt.br/ojs/index.php/afor/article/view/2995/pdf

Carvalho, C. (2021). Projeto que prevê seis pequenas hidrelétricas no Rio Cuiabá ameaça pesca na região. Extra. https://extra.globo.com/noticias/um-so-planeta/projetoque-preve-seis-pequenas-hidreletricas-no-rio-cuiaba-ameaca-pesca-na-regiao-25097599.html

Cunha, E.C.N.D. (2008). Os usos da água para geração de energia elétrica e a sustentabilidade juridico-ambiental. USP. São Paulo. https://www. teses.usp.br /teses /disponiveis/3/3143/tde-30052008-112042/ en.php \# referencias.

ECOA. (2021). Ecologia e Ação, Estudo dos Impactos das Hidrelétricas sobre o Pantanal e a Bacia do Alto Paraguai. 1 vídeo (3 h :36 min. 30 segs.). https://www.youtube.com/watch?v=Zp7ub1eofFk\&t=1724s\&ab_channel=ECOAEcologiaeA\%C3\%A7\%C3\%A3o

Figueiredo, D. M. \& Salomão, F. X. T. (2009). Caracterização e Contextualização. In: Figueiredo, D.M. \& Salomão, F.X.T. Bacia do Rio Cuiabá: uma abordagem socioambiental. Cuiabá: Entrelinhas-Ed. UFMT. 216 P.

Figueiredo, D. M. D., Dores, E. F. G. D. C. \& Lima, Z. M. D. (2018). Bacia do Rio Cuiabá: uma abordagem socioambiental. Ed UFMT, 716 p. https://crbio01.gov.br/arquivos/Bacia\%20do\%20Rio\%20Cuiab\%C3\%A1\%20uma\%20abordagem\%20socioambiental.pdf.

Ferraz, L. (2016). Uso e manejo adaptativo dos recursos pesqueiros por comunidades tradicionais do rio Cuiabá, Pantanal - MT. UFSCar. https://observatoriopantanal.org/wp-content/uploads/ crm_perks_ uploads/ 5cb Of 7347 50a11456042675850236/2019/08/2016_Uso_e_manejo_adapt ativo_dos_recursos_pesqueiros_por_comunidades_tradicionais_do_rio_Cuiaba_Pantanal_MT.pdf\#page=16

Galvão, M.R. C. C. (2016). Pequenas centrais hidrelétricas, comunidades indígenas e espoliação: o Projeto Juruena e os Enawene Nawe no Mato Grosso. 1 recurso online (156 p.). Tese (doutorado) - Universidade Estadual de Campinas, Instituto de Filosofia e Ciências Humanas, Campinas, SP.: <http:// www.repositorio .unicamp.br/ handle/ RE PO SIP/322160

Gomes, E. P. (2014). Potencial de repotenciação de usinas hidrelétricas no Brasil e sua viabilização. Jornal da UNICAMP, 1.

IBGE. (2016). Instituto brasileiro de geografia e estatística. Biblioteca. Acervo dos municípios brasileiros. 
Research, Society and Development, v. 10, n. 11, e206101119533, 2021

(CC BY 4.0) | ISSN 2525-3409 | DOI: http://dx.doi.org/10.33448/rsd-v10i11.19533

Perius, M.R., Carregaro, J.B. (2012). Pequenas centrais hidrelétricas como forma de redução de impactos ambientais e crises energéticas. Ensaios e Ciência, Ciências Biológicas Agrárias e da Saúde. 16(2), 135-150.

Libos, M., Rotunno Filho, O. C., \& Zeilhofer, P. (2003). Modelagem da Poluição não Pontual na Bacia do Rio Cuiabá baseada em geoprocessamento. RBRH Revista Brasileira de Recursos HídricosBrazilian Journal of Water Resources 8(4). https://www.abrhidro.org.br/SGCv3/publicacao.php? $\mathrm{PUB}=1 \& \mathrm{ID}=34 \& S U M A R I O=1530 \& S T=$ modelagem_da_poluicao_nao_pontual_na_bacia_do_rio_cuiaba_baseada_em_geoprocessamento

Lira, J. A. (2014). Pequenos empreendimentos, grandes impactos: estudo das PCHs quanto aos aspectos ideológicos, legais e impactos ambientais na Bacia do Rio Cuiabá com estudo de caso na Sub-Bacia do Rio São Lourenço, em Mato Grosso. Cuiabá, MT Dissertação de mestrado. UFMT.

Lucatelli, L., O. (2021). Projetos de PCHs no Rio Cuiabá podem afetar todo o Pantanal, alerta Lúdio Cabral. Pesquisadores explicam riscos de barragens no Rio Cuiabá, o rio mais importante para pesca e reprodução de peixes no Pantanal. Assembleia Legislativa do Estado de Mato Grosso. https://www.al.mt.gov.br/midia/texto/393/deputado/projetos-de-pchs-no-rio-cuiaba-podem-afetar-todo-o-pantanal-alerta-ludio-cabral/visualizar

Manzano-Agugliaro, F., Alcayde, A., Montoya, F.G., Zapata-Sierra, A. \& Gil, C. (2013). "Scientific production of renewable energies worldwide: An overview," Renewable and Sustainable Energy Reviews, Elsevier, 18(C), 134-143.

Maitelli, G. T. (2005). Interações Amosfera-Superfície. Moreno, G.; Higa, T. C. S. (orgs.). Geografia de Mato Grosso: Território, Sociedade. Cuiabá: Entrelinhas.

Marchetto, M., NoquellI, L. H. M., Andrade, L. A. Z., Silva, M. A. Soares, S. R. A.\& Evangelista, R. M. (2018). Avanços e desafios da política de recursos hídricos quanto aos instrumentos de gestão. In: Bacia do Rio Cuiabá: Uma Abordagem Socioambiental. Figueiredo, D. M., Dores, E. F. G. C. \& Lima, Z. M. (eds.). EdUFMT: Cuiabá. Cap.12, p. 524.

Nilton, C.L. (2009). O impacto das Pequenas Centrais Hidrelétricas - PCH no meio ambiente. https://www.solenerg.com.br/files/tcccassioluizpch.pdf.

O Documento. (2021). Justiça proíbe construção de PCHs no rio Cuiabá e determina medidas urgentes para salvar baías do Pantanal. Cuiabá. https://odocumento.com.br/justica-proibe-construcao-de-pchs-no-rio-cuiaba-e-determina-medidas-urgentes-para-salvar-baias-do-pantanal/.

Oliveira, N. C. C. (2018). A grande aceleração e a construção de barragens hidrelétricas no Brasil. Varia História, Belo Horizonte, 34(65). https://www.scielo.br/j/vh/a/ChCpxyx8Xg6w74xRTmNBRvJ/?format=pdf\&lang=pt

Reis, L. B. (2011). Geração de energia elétrica. Manole Ltda.

Sampaio, L. M. B., Ramos, F. S., Sampaio, Y. (2005). Privatização e eficiência das usinas hidrelétricas brasileiras. Economia Aplicada, 9(3), 465-480. https://www.scielo.br/j/ecoa/a/7xSHtMYJvWDF8x3LFqZ8rMS/?lang=pt\&format=pdf

Terrin, K. A. P., \& Blanchet, L. A. (2019). Direito de energia e sustentabilidade: uma análise dos impactos negativos das usinas hidrelétricas no Brasil. Revista Videre, 11(22), 47-63. https://doi.org/10.30612/videre.v11i22.11215. 